\title{
Optimized Sorption of Methyl Orange using Functionalized Carob Plant Pod
}

\author{
K. A. ABDUlSAlAM ${ }^{1 *}$, B. H. Amodu ${ }^{2}$, O. K. Fakorede ${ }^{2}$, J. M. Adelowo ${ }^{1}$, A. P. Onifade ${ }^{1}$, F. C. \\ Olowosaga $^{1}$, O.D. Omikunle ${ }^{1}$, B. Akintayo ${ }^{1}$, \\ ${ }^{1}$ Department of Basic Sciences, Faculty of Science, Adeleke University, Ede, P.M.B. 250, Osun \\ State, Nigeria \\ ${ }^{2}$ Department of Pure and Applied Chemistry, LadokeAkintola University of Technology, \\ Ogbomoso, Nigeria. \\ *Corresponding author: khadijatpeju@yahoo.com; kdjopalola30@gmail.com, +2348063478938 \\ Received 10 August 2020; accepted 06 September 2020, published online 10 October 2020
}

\begin{abstract}
One of the most problematic groups of water pollutants is dye, a main constituent of textile industrial wastewater, which is carcinogenic. Therefore, this research delved into adsorption of dyes from textiles and wastewater using acid-treated as an adsorbent. The adsorbent was prepared by functionalizing the pod of carob with concentrated $\mathrm{H}_{3} \mathrm{PO}_{4}$. The effects of operational parameters such as adsorbent dosage, contact time, initial concentration of dye and temperature were studied and optimized using central composite design of design of experiment (DOE). The effects of process parameters (contact time, concentration, adsorbent dosage and temperature) on the dye adsorption were determined and optimized. It was observed that the colour removal efficiency increased with an increase in adsorbent mass and contact time. The adsorption process is endothermic as the percentage removal increases with temperature. The optimum contact time, concentration, adsorbent dosage and temperature were found to be $60^{\circ} \mathrm{C}, 9.74 \mathrm{hr}, 10 \mathrm{ppm}$, and $5 \mathrm{~g}$ respectively for the maximum decolorization.
\end{abstract}

Keywords: Adsorption, Optimization, Methyl Orange, Carob Plant, Functionalized pod

\section{Introduction}

In textile dyeing processes, a large volume of dye contaminated effluent is discharged and about $15 \%$ of the dyes used are lost in the effluent Kaushik et al., 2008. This effluent is discharged to the nearby land or channeled into rivers without any prior treatment because the conventional treatment methods are very expensive (Verma and Mishra, 2009). The presence of even a small amount of dye in water is undesirable as it is highly visible, and may be toxic and carcinogenic (Sun and Yung, 2003). Hence, the dye wastewater has to be treated before the eventual discharge of wastewater into the environment (Hameed, 2009). Several physical, biological and chemical removal techniques like flocculation, membrane filtration, adsorption, coagulation, ozonation, radiolysis, bacterial, algal, fungal and advanced oxidation processes have been known to decolourize textile wastewaters (Solmaz et al., 2009; Abdulsalam et al., 2019). Adsorption is a promising technique for wastewater remediation (Abdulsalam et al., 2019). It has great importance due to its ease of operation and comparable low cost of application (Juang et al., 1997; Abdulsalam et al., 2019). This work focused on the optimum conditions for the removal of Methyl Orange (MO) from aqueous solution using functionalized carob plant pod.

\section{Methodology}

\subsection{Preparation of adsorbent}

The adsorbent was prepared by the method of Amode et al., 2013 modified by the method of Giwa et al., 2013. The pod was washed, dried and crushed into powder, then powdered carob pod was soaked in $\mathrm{H}_{3} \mathrm{PO}_{4}$ for 24 hours in ratio $1: 10 \mathrm{w} / \mathrm{v}$, and mixed intermittently by magnetic stirrer. The excess acid was washed with $5 \% \mathrm{w} / \mathrm{v}$ solution of $\mathrm{NaHCO}_{3}$, and then washed with distilled water till a constant $\mathrm{pH}$ was confirmed. Then it was placed in the oven at $160^{\circ} \mathrm{c}$ for 15 hours for activation. Then the powder was sieved using 10-20 $\mu \mathrm{m}$ mesh sieve. The 
adsorbent (PMC) is then placed in an airtight container.
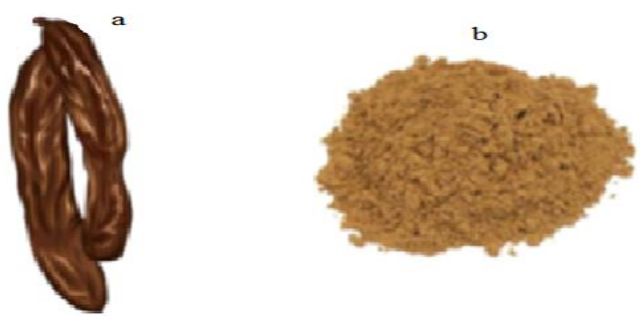

Figure 1: Carobs plant (a) pods and (b) powder (Source: Weng and Pan, 2006).

2.2 Preparation of Methyl orange solutions

A stock solution of Methyl Orange $(100 \operatorname{cs} / \mathrm{N}$ $\mathrm{mg} / \mathrm{L}$ ) was prepared by dissolving $1 \mathrm{~g}$ of the dye in $1 \mathrm{~L}$ volumetric and made up to the mark using distilled water. The prepared. stock solution was then wrapped wi 2. aluminum foil and stored in a dark to preve exposure to direct light.

\subsection{Adsorption experiment}

The adsorption experiments were carried o under ambient conditions by using $a$ temperature regulated mechanical shaker. The adsorbate concentrations were measured by using UV-VIS spectrophotometer at $448 \mathrm{~nm}$. The amount of MO adsorbed was calculated in relation to the initial concentration and the equilibrium concentration.

\subsection{Optimization studies of sorption of methyl orange}

The Central Composite design (CCD) in the Design-Expert software 6.0.8 was used to evaluate the optimum values for adsorption parameters for dye removal from the real wastewater onto the adsorbent. The dependent variable (response) selected for this study is percentage removal which is expressed in percentage (\%) while the independent variables are adsorbent dose, temperature, and contact time. A total of eighteen runs were performed according to a matrix of central composite design.

\subsubsection{Selected factors for adsorption of methyl orange}

The experiments for the adsorption of methyl orange onto PMC were performed at the selected temperature range of $30-60{ }^{\circ} \mathrm{C}$, the contact time of $1-10 \mathrm{~h}$, the concentration of $10-50 \mathrm{ppm}$ and an adsorbent dose of $1.0-$ $5.0 \mathrm{~g}$. The factors level design is given in Table 1. The response was expressed as percentage color removal, $\% \mathrm{R}$, calculated as:

$\% \mathrm{R}=(\mathrm{C} 0-\mathrm{Ce}) / \mathrm{C} 0 \times 100$

Where, $\mathrm{Co}$ and $\mathrm{Ce}$ are the initial and equilibrium concentrations of the dye in $\mathrm{mg} / \mathrm{L}$ respectively.

Table 1: Adsorption Factors Level Design

\begin{tabular}{|c|c|c|c|c|c|}
\hline Variables & Type & $\begin{array}{l}\text { Actu } \\
\text { Valu }\end{array}$ & & $\begin{array}{l}\text { Code } \\
\text { Valu }\end{array}$ & \\
\hline & & Low & High & Low & High \\
\hline Dosage (g) & Numeric & 1 & 5 & -1 & 1 \\
\hline $\begin{array}{l}\text { Temperature } \\
\left({ }^{\circ} \mathrm{C}\right)\end{array}$ & Numeric & 30 & 60 & -1 & 1 \\
\hline Time (hr) & Numeric & 1 & 10 & -1 & 1 \\
\hline $\begin{array}{l}\text { Concentration } \\
(\text { ppm) }\end{array}$ & Numeric & 10 & 50 & -1 & 1 \\
\hline
\end{tabular}

\subsubsection{Statistical analysis for color removal from PMC}

Statistical analysis was done using Model Summary Statistics, Analysis of Variance (ANOVA), and Diagnostic Case Studies.

\section{Data, value, and validation}

\subsection{Application of statistical analysis}

ANOVA is a statistical method that reveals the power of the relationship with the sources of variation determined to test hypotheses on the total variance of the data used in the experiment on the parameters of the applied model (Giwa et al., 2018). ANOVA analysis for the second-order equations is shown at Table 2. In the ANOVA analysis, the relationship between the response of the equation and the significant variables was adequately represented. According to ANOVA (Table 2), the $\mathrm{F}$ values of all regressions are very high. The associated p-value is used to determine whether $\mathrm{F}$ is statistically important. The fact that each p-value is lower than 0.05 indicates that the applied model is statistically 
important (Ahmad et al., 2015; Abdulsalam et al., 2017)

The model F-value of 3.54 implies the model is significant. There is only a $3.65 \%$ chance that a "ModelF-value" this large could occur due to noise. Values of "Prob>F" less than 0.0500 indicate model terms are significant. In this case $\mathrm{A}$ is the significant model term. Values greater than 0.1000 indicate the model terms are not significant. If there are many insignificant model terms (not counting those required to support hierarchy), model reduction may improve your model.

Table 2: ANOVA for Response Surface Linear Model

\begin{tabular}{lllllll}
\hline & Sum of & \multicolumn{3}{c}{ Mean } & F & \multicolumn{2}{l}{ Prob } & \\
Source & Squares & DF & & Value & $>$ F & \\
\hline Model & 216.78 & 4 & 54.195 & 3.540 & 0.037 & Sig \\
& & & 175.6 & & & \\
A & 175.62 & 1 & 2 & 11.471 & 0.005 & \\
B & 9.1386 & 1 & 9.1386 & 0.5969 & 0.454 & \\
C & 22.875 & 1 & 22.875 & 1.4942 & 0.243 & \\
D & 9.0129 & 1 & 9.0129 & 0.5887 & 0.457 & \\
Residual & 199.02 & 13 & 15.310 & & & \\
Lack of & & & & & & not \\
Fit & 197.22 & 12 & 16.434 & 9.1053 & 0.253 & sig \\
\hline
\end{tabular}

The "Lack of fit f-value" of 9.11 implies the lack of fit is not significant relative to the pure error. There is a $25.39 \%$ chance that a "lack of fit f-value" this large could occur due to noise. Nonsignificant lack of fit is good since it is good for the model to fit.

\subsection{Effect of adsorption parameters}

\subsubsection{Effect of Adsorbent dose}

The dependence of the percentage dye removal on the amount of PMC is depicted in Figure 2. It was observed that the \% MO removal increased with an increase in adsorbent mass. This trend may be attributed to the availability of more adsorption sites and increasing pore surface areas with increasing adsorbent doses. It makes penetration of adsorbate molecules into the adsorption sites easier to the large vacant sites available to be accessed by the dye molecules present in the wastewater under investigation (Kumar et al., 2007; Hassanein and Koumanova, 2010; Abdulsalam et al., 2020)

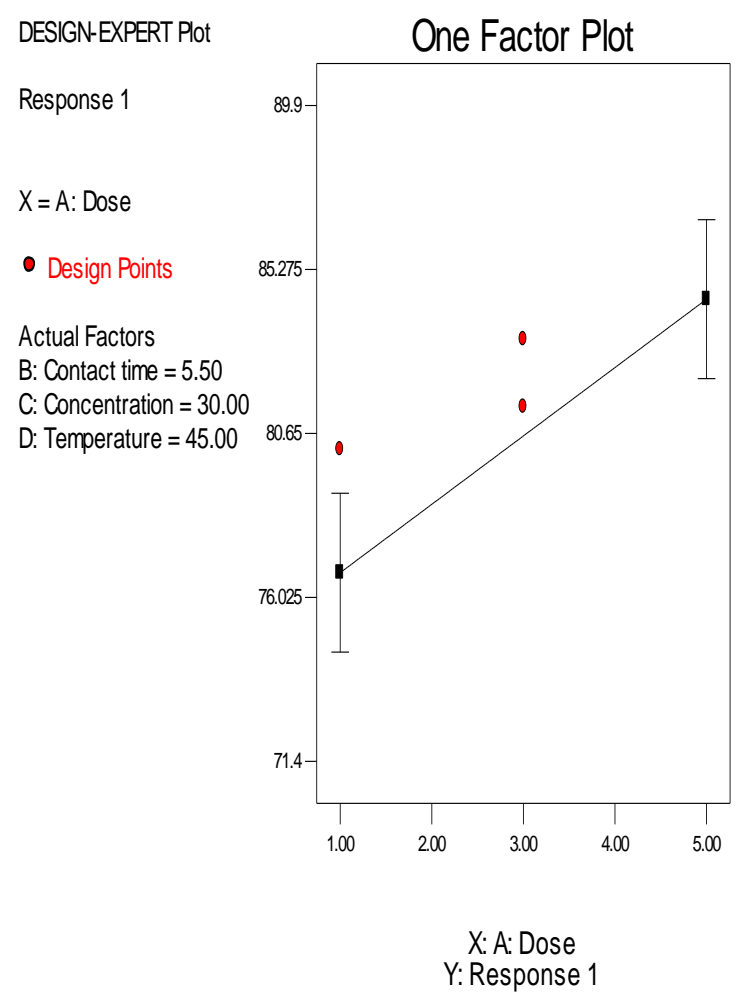

Figure 2: Effects of Adsorbent dose

\subsubsection{Effects of contact time}

The effects of contact time on the removal of methyl orange unto PMC was investigated by varying the contact time in the range of $1-10 \mathrm{~h}$, while keeping doses, concentration and temperature constant. Fig. 3 shows the relationship between contact time and percentage dye removal. Percentage dye removal increased with 
increasing contact time until equilibrium is established (Jabli et al., 2011; Ahmad et al., 2019; Abdulsalam et al., 2020).

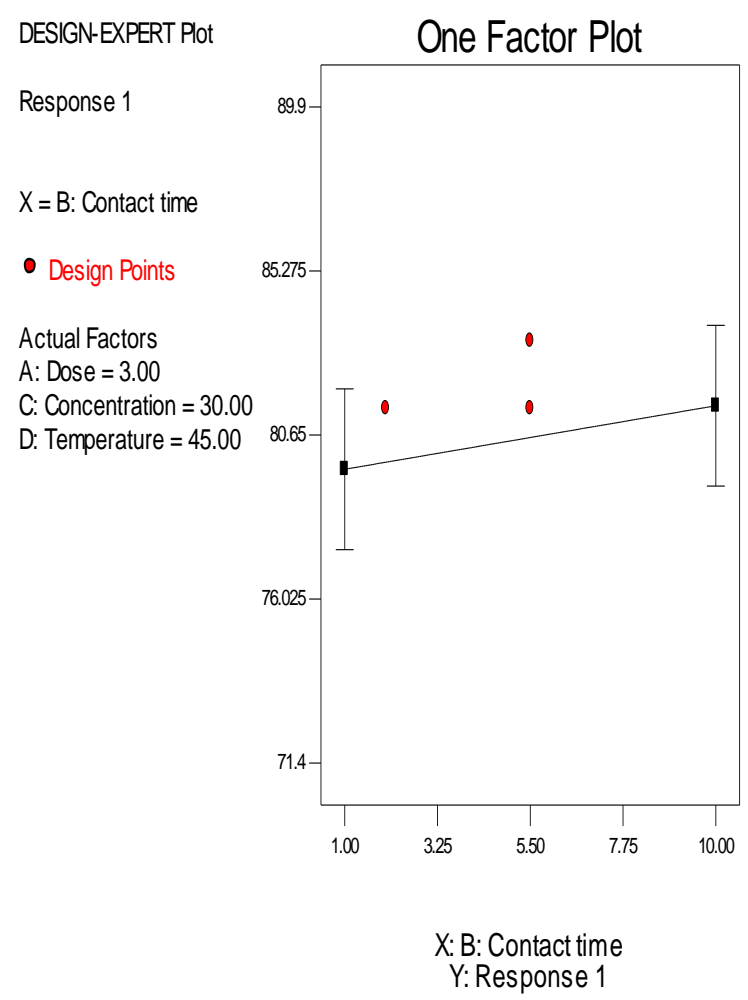

Figure 3: Effects of Contact time

\subsubsection{Effect of temperature}

The removal percentage increases with increasing temperature for the methyl orange as depicted in Figure 4. This indicates that the adsorption is an endothermic process. The increase in efficiency with temperature may be due to the increase in the mobility of the dye molecules. This implies that chemically interactions of PMC surface functionality with dyes present in the textile wastewater increases which further enhanced the penetration of the dye molecules onto the PMC pores (Singh and Srivastava, 2001; Verma and Mashra 2010; Abdulsalam et al., 2020)

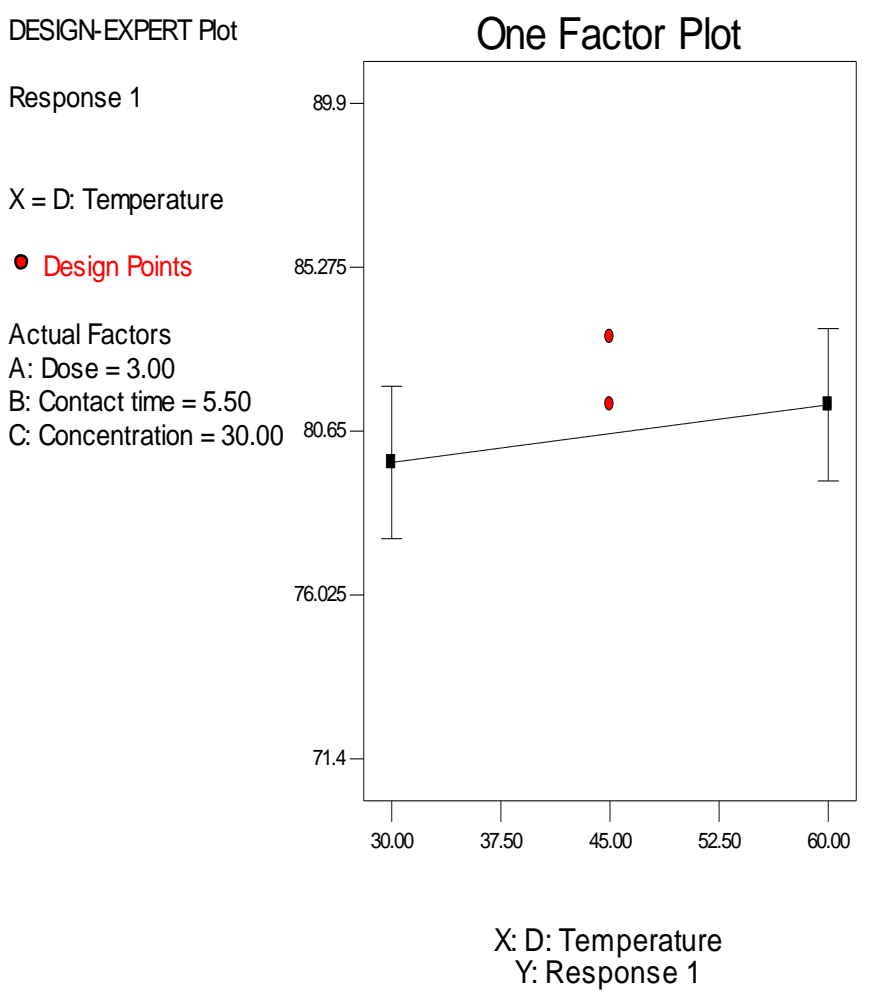

Figure 4: Effects of Temperature 


\subsubsection{Effect of concentration}

The relationship between percentage MO removal onto PMC and dye concentration is depicted in Figure 5. Increase in initial MO concentration leads to decrease in the adsorption of MO on carob pod. This may be due to saturation of available pores on the adsorbent (Giwa et al., 2015; 2016)

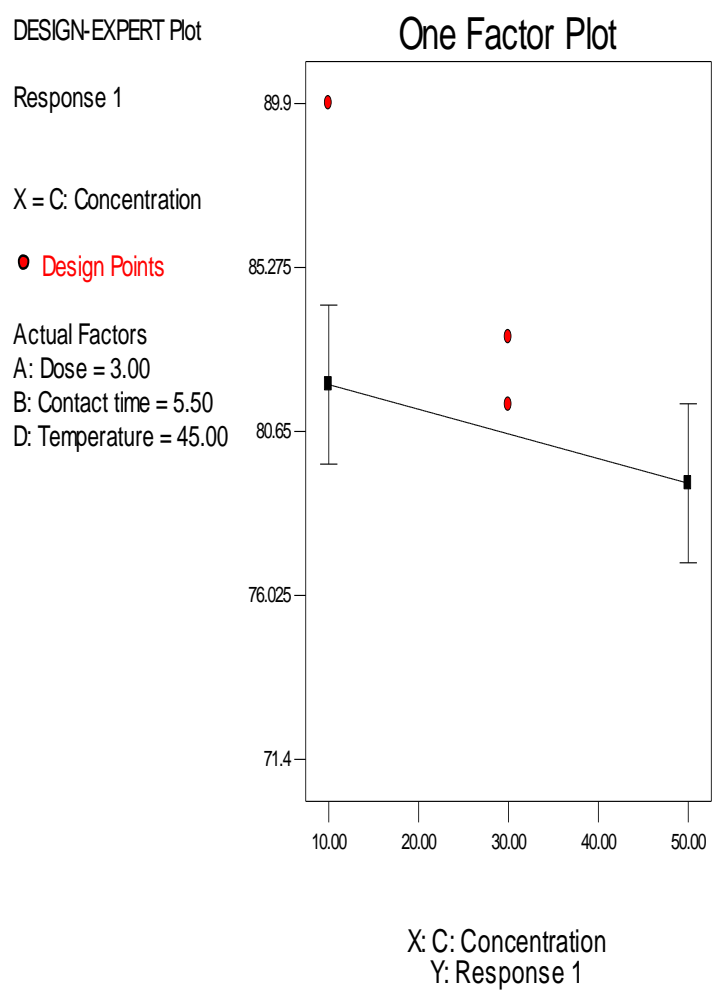

Figure 5: Effects of Dye Concentration

\subsection{Diagnostic Case Study}

The results of the diagnostic case study are given in Figure 6 and 7. It is a plot of residual values against predicted values. The actual values indicate the percentage of dye removed and the predicted values indicate the standard generated by the software. The residual shows the closeness of the actual values to the predicted values, it can therefore be either positive or negative or zero. Negative values of residuals indicate that the actual value is greater than the predicted value while positive value indicates that the predicted value is greater than the actual value. Residual value of zero is an indication that the actual amount is equal to the predicted value on which the comparison is made as shown in the scatter of Figure 8 (Abdulsalam et al., 2020).

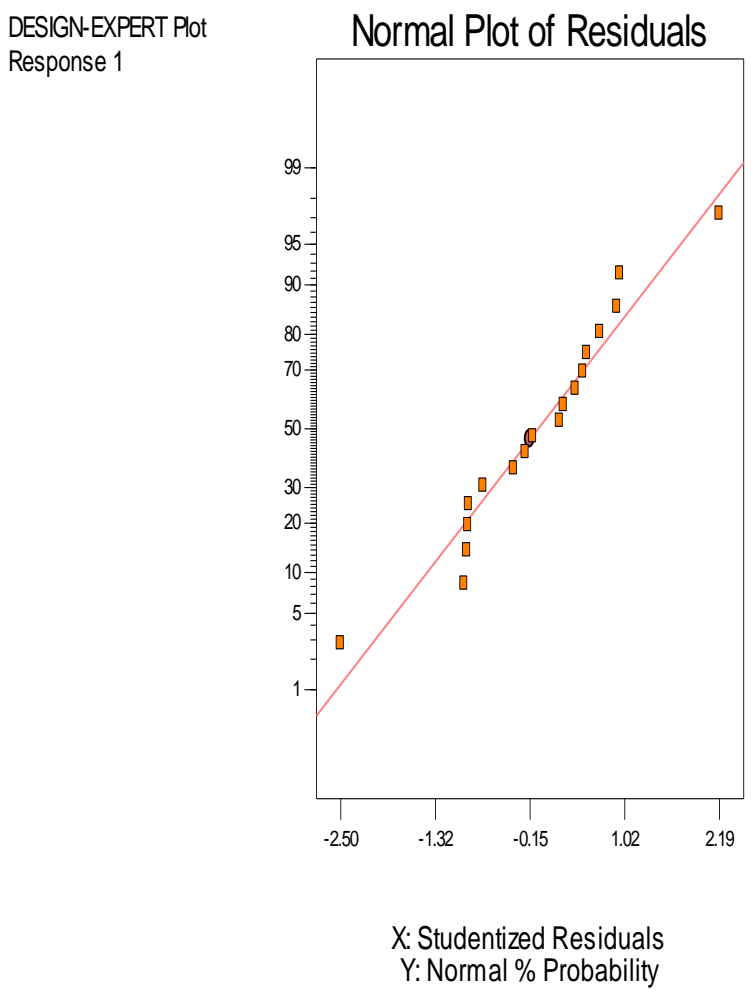

Figure 6: Plot of Studentized Residuals 
DESIGN-EXPERT Plot Response 1

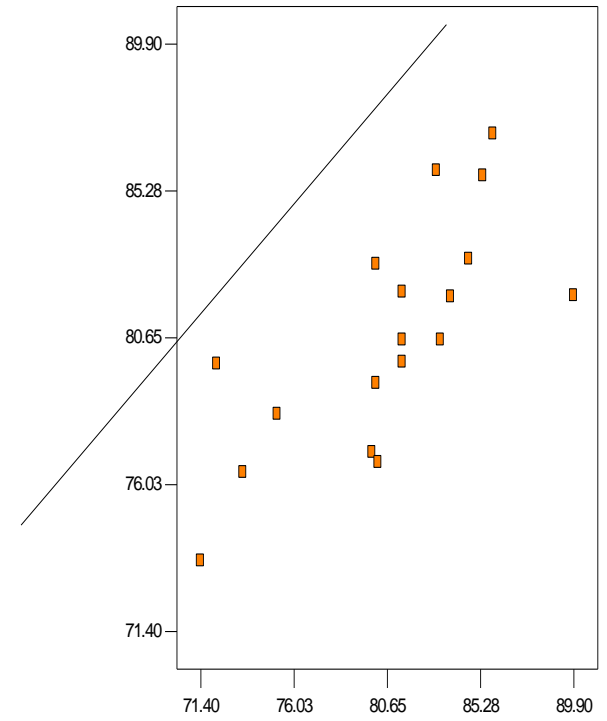

$X:$ Actual Y: Predicted

Figure 7: Plot of Predicted values against Actual values

\subsection{Optimization of percentage removal}

Optimization was used by the model to give the specific values (level) for each of the independent variables that gave optimum adsorption. The optimum conditions required for the adsorption of $10.00 \mathrm{mg} / \mathrm{L}$ of MO (87.49\% removal with a desirability of 0.93$)$ in the presence are: adsorbent dose of $5 \mathrm{~g}$, temperature of $60^{\circ} \mathrm{C}$, and contact time of $9.74 \mathrm{hr}$.

\section{Conclusion}

The effects of operational parameters such as adsorbent dosage, contact time, initial concentration of dye and temperature were studied and optimized using central composite design of design of experiment (DOE). The effects of process parameters (contact time, concentration, adsorbent dosage and temperature) on the dye adsorption were determined and optimized. It was observed that the colour removal efficiency increased with an increase in adsorbent mass and contact time. The adsorption process is endothermic as the percentage removal increases with temperature. The optimum conditions required for the adsorption of $10.00 \mathrm{mg} / \mathrm{L}$ of $\mathrm{MO}(87.49 \%$ removal with a desirability of 0.93 ) in the presence are: adsorbent dose

\section{Acknowledgments}

The authors acknowledge the technologists of Department of Chemistry of both Adeleke University and Ladoke Akintola University of Technology, Nigeria.

\section{References}

K. A. Abdulsalam, A. E. Adeleke, J. M. Adelowo, A. K. Oyebamiji, A. P. Onifade, and F. C. Olowosaga (2019b), Optimized Decolourization of Textile Wastewater: A Review, International Journal of Modern Analytical and Separation Sciences, 7(1): 1435.

K. A. Abdulsalam, A. A. Giwa, and J. M. Adelowo (2020), Optimization studies for decolourization of textile wastewater using a sawdust-based adsorbent, Chemical Data Collections, 27 (100400): 1-11.

K. A. Abdulsalam, A. A. Giwa F. Wewers, and A. Arinkoola (2017), Optimization studies on the Adsorption of Malachite green from quaternary dye mixture using modified sawdust of Locust bean tree, Journal of Environment and Biotechnology Research, 6 (1): $128-136$.

M. Ahmad, N. Ahmed, K. Adegoke, and O. Bello (2019), Sorption studies of methyl red dye removal using lemon grass (Cymbopogon citratus), Chem. Data Collect, 22: 100249.

M. Ahmad, N. Afandi, and O. Bello (2015) Optimization of process variables by response surface methodology for malachite green dye removal using lime peel activated carbon, Applied Water Science, 7: 717 - 727.

J. O. Amode, J. H. Santos, Z. Alam, A. Mirza, and C. C. Mei (2016), Adsorption of methylene blue from aqueous solution using untreated and treated metroxylon spp waste adsorbent: equilibrium and kinetics studies, International Journal of Indian Chemistry, 7: 333-345. 
A. A. Giwa, K. A. Abdulsalam, M. A. Oladipo, and A. O. Ibrahim (2018a) Adsorption of crystal violet from quaternary dye mixture onto sawdust: statistical analysis and optimization studies, Journal of Environment and Biotechnology Research, 7(4): 54-63.

A. A. Giwa, K. A. Abdulsalam, F. Wewers, and M. Oladipo (2016), Biosorption of acid dye in single and multi-dye systems onto sawdust of locust bean (Parkia biglobosa) tree, Journal of chemistry, 6436039: 1- 31 .

A. Giwa, M. Oladipo, and K. Abdulsalam (2015), Adsorption of Rhodamine B from single, binary and ternary dye systems using Sawdust of Parkia biglobosa as adsorbent: Isotherm, kinetics and thermodynamics studies, Journal of Chemical and Pharmaceutical Research, 7:454475 .

A. A. Giwa, I. A. Bello, and A. A. Olajire (2013), Removal of basic dyes from aqueous solution by adsorption on melon husk in binary and ternary systems, Chemical Process and Engineering Reources, 13: 51 -68.

B. H Hameed (2009), Spent tea leaves: A new non-conventional and low-cost adsorbent from removal of basic dye from aqueous solutions, Journal of Hazardous Materials, 161: 753 -759.

F. T. Hassanein, and B. C. Koumanova (2010), Evaluation of Adsorption Potential of the Agricultural Waste Wheat Straw for Basic Yellow 21, Chemistry and Technology, 4594: $407-414$.

M. Jabli, M. V. Baouab, M. S. Roudesli, A. L. Bartegi (2011), Adsorption of Acid dyes from aqueous solution on a chitosan-cotton composite material prepared by a new pad-dry process, Journal of engineered fibers and fabrics, 6: 1 12.

R. S. Juang, F. C. Wu, and R. L. Iseng (1997), The ability of activated clay for the adsorption of dyes from aqueous solutions. Environmental Technology, 18: $525-531$.

N. Kaushik, C. Kaushik, R. Tuteja, and J. Sharma (2008), Studies on adsorption of triazine dyes by natural and chemical modified agro waste materials, Rasayan Journal of Chemistry, 1: 819-827.

K. V. Kumar, and K. Porkodi (2007), Mass transfer, kinetics and equilibrium studies for the biosorption of methylene blue using Paspalum notatum, Journal of Hazardous Material, 146: 214-226.

D. K. Singh, and B. (2001), Srivastava Basic dyes removal from wastewater by adsorption on rice husk carbon, Indian Journal of Chemical Technology, 8: 133-139.

A. Solmaz, S. K. Ustun, G. E. Birgul, and A. Yonar (2009), Advanced oxidation of Textile dyeing effluents: comparison of $\mathrm{Fe} 2+$ l $\mathrm{H} 2 \mathrm{O} 2$, $\mathrm{Fe} 3+/ \mathrm{H} 2 \mathrm{O} 2$, O3and chemical coagulation processes, Fresenius Environmental Bulletin, 18: 1424-1433.

Q. Sun, and L. Yung (2003), The adsorption of basic dyes from aqueous solution on modified peat - resin particle, Water Research, 37: 1535-1544.

V. K. Verma, A. K. Mishra (2010), Kinetic and isotherm modeling of adsorption of dyes onto rice husk carbon, Global Nest Journal, 12: 190-196.

C. H. Weng, Y. F. Pan (2006), Adsorption characteristics of methylene blue from aqueous solution by sludge ash Colloids, Surf. A. Physicochem. Engineering, 274: 154-162. 